\title{
Comparison of Growth Performance and Meat Quality Traits of Commercial Cross-Bred Pigs versus the Large Black Pig Breed
}

\author{
Yongjie Wang ${ }^{1}$, Keshari Thakali ${ }^{2}$, Palika Morse ${ }^{1}$, Sarah Shelby ${ }^{1}$, Jinglong Chen ${ }^{3}$, Jason Apple ${ }^{4}$ and \\ Yan Huang $1, * \mathbb{D}$
}

check for

updates

Citation: Wang, Y.; Thakali, K.;

Morse, P.; Shelby, S.; Chen, J.; Apple, J.; Huang, Y. Comparison of Growth Performance and Meat Quality Traits of Commercial Cross-Bred Pigs versus the Large Black Pig Breed. Animals 2021, 11, 200. https://doi. org/10.3390/ani11010200

Received: 18 November 2020 Accepted: 13 January 2021 Published: 15 January 2021

Publisher's Note: MDPI stays neutral with regard to jurisdictional clai$\mathrm{ms}$ in published maps and institutional affiliations.

Copyright: (C) 2021 by the authors. Licensee MDPI, Basel, Switzerland. This article is an open access article distributed under the terms and conditions of the Creative Commons Attribution (CC BY) license (https:// creativecommons.org/licenses/by/ $4.0 /)$.
1 Department of Animal Science, Division of Agriculture, University of Arkansas, Fayetteville, AR 72701, USA; yw030@uark.edu (Y.W.); pdias@uark.edu (P.M.); sshelby@uark.edu (S.S.)

2 Arkansas Children's Nutrition Center, Department of Pediatrics, University of Arkansas for Medical Sciences, Little Rock, AR 72207, USA; KMThakali@uams.edu

3 Key Laboratory of Animal Physiology \& Biochemistry, College of Veterinary Medicine, Nanjing Agricultural University, Nanjing 210095, China; 2017207005@njau.edu.cn

4 Department of Animal Science and Veterinary Technology, Texas A\&M University, Kingsville, TX 78363, USA; Jason.Apple@tamuk.edu

* Correspondence: yxh010@uark.edu

Simple Summary: Emphasis on improving meat quality is growing in the meat industry. Pigs under the same diet and environment could present with difference in meat quality if they have diverse genetic backgrounds. The Large Black pig is a British native pig breed which is famous for its hardness and resistance to extensive farming; compared with commercial cross-bred pigs, they have a slower growth rate. The aim of this study is to investigate the carcass and meat quality traits of Large Black pigs and commercial cross-bred pigs in relation to their transcriptome profiles, and consequently clarify the phenotypic and genotypic differences between these two groups of pigs. The results showed that Large Black pigs had greater intramuscular fat content than commercial cross-bred pigs, while the growth performance of commercial cross-bred pigs was better, and the transcriptomic differences between these two groups of pigs may be the cause of meat quality and growth performance variances. The outcome of the study provides new sights into the adoption of the Large Black breed in the pig industry.

Abstract: The meat quality of different pig breeds is associated with their different muscle tissue physiological processes, which involves a large variety of genes related with muscle fat and energy metabolism. Understanding the differences of biological processes of muscle after slaughter is helpful to reveal the meat quality development of different breeds. Therefore, eight native Large Black pigs (BP), with high fat content in meat, and seven cross-bred commercial pigs (CP), which had a high feed efficiency with high lean meat, were used to investigate the differences in their meat quality and RNA transcriptomes. The average daily gain (ADG) and hot carcass weight (HCW) of CP were higher than BP, but the back-fat thickness of BP was higher than $\mathrm{CP}(p<0.05)$. The $\mathrm{CP}$ had higher $\mathrm{a}^{*}$ (redness) but lower $\mathrm{h}$ (hue angle) than BP $(p<0.05)$. The metmyoglobin $(\mathrm{MMb})$ percentage of $\mathrm{CP}$ was higher $(p<0.05)$ than BP. The fat content and oxygen consumption of longissimus dorsi (LD) muscles in BP were higher $(p<0.05)$ than CP. BP had higher monounsaturated fatty acids (MUFA) content, but CP had higher polyunsaturated fatty acids (PUFA) content $(p<0.05)$. The RNA-seq data highlighted 201 genes differentially expressed between the two groups (corrected false discovery rate (FDR) $p<0.05$ ), with 75 up-regulated and 126 down-regulated genes in BP compared with $\mathrm{CP}$ using the fold change (FC). The real-time PCR was used to validate the results of RNA-seq for eight genes, and the genes related to lipid and energy metabolism were highly expressed in BP $(p<0.05)$. Based on the results, BP had superior intramuscular fat content to $\mathrm{CP}$, while the growth performance of $\mathrm{CP}$ was better, and the transcriptomic differences between these two groups of pigs may cause the meat quality and growth performance variance.

Keywords: commercial cross-bred; purebred; meat quality; intramuscular fat; RNA-seq 


\section{Introduction}

Increasing the carcass weight and leanness of pigs has been a strong emphasis in production efficiency in swine breeding programs for many years. The researchers concentrated on improving pork production, such as the growth rate and feed conversion ratio, and they also aimed at decreasing carcass fat content and backfat thickness. However, pork quality has received a prime focus on pig production as consumers demand better meat quality, for example, tenderness, marbling, color, and water holding capacity (WHC) [1]. The interactive effects of pig breeds, environmental situations, pre-harvest management and post-harvest processes result in different meat qualities [2]. However, the effects of genotypes on meat quality are generally higher than external feed conditions [3]. It was reported that meat quality was also related to postmortem meat metabolism, and the oxygen consumption of muscle tissue is one of its metabolic phenotypes [4]. In addition, a large variety of genes related to both muscle structures and metabolic substances could affect the postmortem physiological developments inside the muscle cells. Comparing the transcriptome expression profile differences between different breeds could help us to understand the principles of genes related with meat quality and muscle biological processes.

Commercial cross-bred pigs (CP) are widely used in pig industry for its great feed efficiency and higher average daily gain (ADG), with high productivity of lean meat and less fat content. In contrast, the Large Black pigs (BP) are British native pigs with a long and deep-bodied shape. They are well known for their high fat content and high meat quality characteristics $[5,6]$.

The aim of this experiment was to investigate the carcass and meat quality traits of Large Black pigs (BP) and commercial cross-bred pigs (CP) in relation to their transcriptome profiles, and consequently clarify the phenotypic and transcriptomic differences between these two groups of pigs. The outcome of the study provided new sights into the adoption of the Large Black breed in the pig industry. In order to investigate the differences of gene expression between $\mathrm{BP}$ and $\mathrm{CP}$, the RNA-seq methodology, which is widely used to provide a comprehension transcriptomic profile of analyzed tissue, has been applied $[7,8]$. Based on RNA-seq results, functional analysis of gene ontology (GO) and biological processes were used to highlight enriched relevant biological pathways $[9,10]$. In addition, the real-time PCR was used to support the RNA-seq data.

\section{Material and Methods}

\subsection{Animals}

The University of Arkansas's Institutional Animal Care and Use Committee approved all procedures of the experiment involving animals during the study (ethical approval code: 18,000). Eight Large Black pigs and seven commercial cross-bred pigs (PIC 29 dam $\times$ PIC 380 boar) were allocated to the $\mathrm{BP}$ group and $\mathrm{CP}$ group, and their initial mean body weights were tabulated $(23.31 \pm 1.93 \mathrm{~kg}$ for the BP group and $18.82 \pm 1.41 \mathrm{~kg}$ for the CP group). They were fed ad libitum and kept individually in digestibility pens for 101 days. The final body weight of the $\mathrm{CP}$ group was determined at the end of the 101-day experiment. However, due to low growth performance of the BP, the average body weight of BP group was $115.4 \mathrm{~kg}$, lower than the average market live weight, which is $127.9 \mathrm{~kg}$ [11]. The BP group was kept for 108 days. The differences between the initial and final body weight was used to calculate the ADG. Animals were fasted $12 \mathrm{~h}$ prior to slaughter, with access to water. Then, they were rendered unconscious by a nonpenetration stunning method.

\subsection{Carcass Characteristics and Sampling}

Immediately after stunning and completion of exsanguination, hot carcass weight (HCW) and backfat thickness (midline, between the 4th and 5th lumbar vertebra level) were determined. Then, muscle samples of longissimus dorsi (LD) of the left carcass was removed, and the samples were snap frozen at $-80^{\circ} \mathrm{C}$ in liquid nitrogen for RNA isolation process. The carcasses were chilled at $-9{ }^{\circ} \mathrm{C}$ for two hours and then kept at $4{ }^{\circ} \mathrm{C}$ for $24 \mathrm{~h}$. 
Another piece from the LD muscle was obtained (between the 12th and 13th rib) and transported under refrigeration until being processed for meat quality. The muscles were cut into small pieces, vacuum-packed, and stored at $-20{ }^{\circ} \mathrm{C}$ before analyzing the fatty acid profile.

\subsection{Meat Quality}

The intramuscular fat (IMF) content of the longissimus dorsi muscle was determined by using Soxhlet apparatus to extract ether without prior acid hydrolysis [12]. A $100 \mathrm{~g}$ thick slice cut from the LD muscle was placed into a polypropylene bag and then stored in a vacuum package for $24 \mathrm{~h}$ at $4{ }^{\circ} \mathrm{C}$, and the weight differences of samples were regarded as drip loss, showed as percentages [13]. In order to ensure stable data of color measurements, samples were bloomed for $20 \mathrm{~min}$ before further analysis. The Lightness (L), red to green $\left(a^{*}\right)$, and yellow to blue $\left(b^{*}\right)$ color values were determined by a CR-400 Chroma Meter. Then, the hue angle $\left(h=\arctan \left(b^{*} / a^{*}\right)\right)$ and chroma $\left(C^{*}=\left(\left(a^{*}\right)^{2}+\left(b^{*}\right)^{2}\right)^{0.5}\right)$ were calculated using the $\mathrm{L}, \mathrm{a}^{*}$, and $\mathrm{b}^{*}$ values.

\subsection{Fatty Acid Composition}

The fatty acid composition of LD muscle IMF was determined by fat extraction [14]. Ten grams of minced meat were homogenized at $3000 \mathrm{rpm}$ for $1.5 \mathrm{~min}$ by UltraTurrax using $0.003 \%$ butylhydroxytoluene (BHT) with $200 \mathrm{ml}$ Folch solution (chloroform-methanol mix 2:1). After paper-filtering (Whatman No. 1) the homogenized liquid, Folch solution (50 mL) was added. After filtering, the solution was poured out into a decantation infundibulum and mixed with $8 \%$ sodium chloride $(80 \mathrm{~mL})$ for $24 \mathrm{~h}$. The solvent, collected from the lipidic phase, was evaporated. After evaporation, the fatty acid composition was analyzed using gas chromatography (Agilent $6890 \mathrm{~N}$ Network GC System). As a carrier gas, helium was used at a division ratio of 1:50 with a $3.2 \mathrm{ml}$ per minute flow rate. The undecanoic acid methyl ester was used as an internal standard to quantify the methyl esters of fatty acids.

\subsection{Oxygen Consumption and Myoglobin Calculation}

Approximately $20 \mathrm{mg}$ of tissue from the longissimus dorsi (LD) muscle from each sample was put into a respiration buffer (1.1 $\mathrm{mM}$ sodium pyruvate, $25 \mathrm{mM}$ glucose in PBS and $2 \%$ BSA). The oxygen consumption rate (OCR) of every sample was measured by an Orion Dissolved Oxygen Platform (Scientific) about $25 \mathrm{~min}$ and repeated 3 times. A full reflectance spectral analysis was also taken on each muscle, and wavelength ratios were used to calculate relative deoxymyoglobin $(474: 525 \mathrm{~nm})$, oxymyoglobin $(610: 525 \mathrm{~nm})$, and metmyoglobin (572:525 $\mathrm{nm}$ ) concentrations [15].

\subsection{RNA Extraction and cDNA Synthesis}

The total RNA of longissimus dorsi muscles was extracted by TRIzol Reagent (Invitrogen, Carlsbad, CA, USA) with mechanic homogenization by using the Precellys Evolution homogenizer (Bertin Technologies, Rockville, MD, USA). The total RNA, extracted from the muscle, was then treated with DNase I (Promega, Madison, WI, USA) to eliminate the contamination of genomic DNA, following the directions of the manufacturer. The concentration of total RNA was assessed by NanoDrop (Agilent Technologies, CA, USA). The same RNA extracts were used both for real-time qPCR and RNA sequencing later. Reverse transcription of the decontaminated RNA samples was performed using Takara PrimeScript ${ }^{\mathrm{TM}} \mathrm{RT}$ reagent kit, and then prepared for cDNA synthesis according to the instructions of Takara PrimeScript ${ }^{\mathrm{TM}}$ RT.

\subsection{Statistical Analysis}

All the data analysis was performed using SPSS version 19.0 software (SPSS Inc., Chicago, IL, USA). The differences of mean values of these two groups were carried out using $t$-tests of independent samples. The results are given as means and SD in the text, and the differences were considered significant when $p<0.05$. 


\subsection{Real-Time qPCR}

According to the recorded sequences showed in GenBank, the primers of $S L C 26 A 7$, TKTL2, ACBD7, THRSP, SLPI, FADS1, ACSL6, FOS and GAPDH were designed using Oligo 6.0 Software, and they were designed to span the introns to make sure the correct cDNAs are amplified (Table 1). GAPDH gene has been widely used as a housekeeping gene normalizer [16], and was thus selected as a reference in the present study. The cDNA was used to perform real-time PCR in order to obtain the expression levels of SLC26A7, TKTL2, ACBD7, THRSP, SLPI, FADS1, ACSL6, FOS. Real-time-qPCR was performed using $15 \mu \mathrm{L}$ reaction system: $7.5 \mu \mathrm{L} 2 \times$ Real Master Mix; $0.75 \mu \mathrm{L}$ upstream and 0.75 downstream primer $(10 \mathrm{pmol} / \mathrm{L}) ; 3 \mu \mathrm{L} c \mathrm{CNA}$; and $3 \mu \mathrm{L}$ water. The reaction liquid was added on iCycler $\mathrm{IQ}^{5}$ (Bio-Rad, USA). Technical duplicates were applied for the qPCR analysis. The PCR procedure was denaturing the DNA at $95^{\circ} \mathrm{C}$ for $3 \mathrm{~min}$, followed by 40 cycles of denaturation at $95{ }^{\circ} \mathrm{C}$ for $15 \mathrm{~s}$, and annealing/extension at $55^{\circ} \mathrm{C}$ for $30 \mathrm{~s}$. Relative expression levels were normalized to the GAPDH gene and expressed as fold change [17]. The software CFX manager (Bio-Rad, USA) was used to process $\mathrm{Ct}$ values, and the delta-delta $\mathrm{Ct}$ method was used to calculate the fold change.

Table 1. Primer information for genes chosen for confirmation of expression using quantitative real-time PCR.

\begin{tabular}{|c|c|c|c|c|c|}
\hline Gene & Direction & Primer Sequence & GenBank Accession No. & Binding Positions & Product Length (bp) \\
\hline \multirow{2}{*}{ GAPDH } & Forward & $5^{\prime}$-TCGGAGTGAACGGATTTGGC-3' & \multirow{2}{*}{ NM_00120659.1 } & 111 & \multirow{2}{*}{189} \\
\hline & Reverse & $5^{\prime}$-TGACAAGCTTCCCGTTCTCC-3' & & 299 & \\
\hline \multirow{2}{*}{ SLC26A7 } & Forward & $5^{\prime}$-GAAAATGCCAGCAATCAGCCA-3' & \multirow{2}{*}{ XM_021089130.1 } & 1837 & \multirow{2}{*}{102} \\
\hline & Reverse & $5^{\prime}$-AGGGCCACAGTTCCCATTG-3' & & 1938 & \\
\hline \multirow{2}{*}{ TKTL2 } & Forward & $5^{\prime}$-CTGGCCTTTGCATCCCACTA-3' & \multirow[b]{2}{*}{ XM_013978706.2 } & 373 & \multirow[b]{2}{*}{104} \\
\hline & Reverse & $5^{\prime}$-GTATCCATGCAGTGCGCAAG-3' & & 476 & \\
\hline \multirow{2}{*}{$A C B D 7$} & Forward & $5^{\prime}$-GGAAGATGCCATGAGTGCCT-3' & \multirow[b]{2}{*}{ XM_003357745.4 } & 259 & \multirow[b]{2}{*}{104} \\
\hline & Reverse & $5^{\prime}$-CTGAGGGCTTCAAAAGGCAAA-3' & & 362 & \\
\hline \multirow{2}{*}{ THRSP } & Forward & 5'-GTAGCCTCGGACTCTAGGCA-3' & \multirow{2}{*}{ NM_001244376.1 } & 486 & \multirow[b]{2}{*}{114} \\
\hline & Reverse & 5'-CTGCAGGTCCAGGTCTTTCT-3' & & 599 & \\
\hline \multirow{2}{*}{ SLPI } & Forward & $5^{\prime}$-CAAGTGCACAAGTGACTGGC- $3^{\prime}$ & \multirow{2}{*}{ NM_213870.1 } & 139 & \multirow{2}{*}{137} \\
\hline & Reverse & 5'-GGCCATAGACCACTGGACAC-3' & & 275 & \\
\hline \multirow{2}{*}{ FADS1 } & Forward & 5'-GTCACTGCCTGGCTCATTCT-3' & \multirow{2}{*}{ NM_001113041.1 } & 433 & \multirow{2}{*}{155} \\
\hline & Reverse & 5'-AGGTGGTTCCACGTAGAGGT-3' & & 587 & \\
\hline \multirow[b]{2}{*}{ ACSL6 } & Forward & $5^{\prime}$-GAATACGGGCACTCTCTGGC-3' & \multirow[b]{2}{*}{ XM_021084743.1 } & 44 & \multirow[b]{2}{*}{130} \\
\hline & Reverse & $5^{\prime}$-CCTAGGACCCCAGTTTGCAG-3' & & 173 & \\
\hline \multirow{2}{*}{ FOS } & Forward & $5^{\prime}$-GACTGCTATCTCGACCAGCC-3' & \multirow{2}{*}{ NM_001123113.1 } & 192 & \multirow{2}{*}{158} \\
\hline & Reverse & $5^{\prime}$-CTGGCATGGTCTTCACGACT-3' & & 349 & \\
\hline
\end{tabular}

\subsection{RNA Sequencing and Functional Analysis}

The RNA was isolated from the longissimus dorsi muscle using Trizol reagent as described above. Three micrograms of total RNA were used to isolate poly-A RNA using the Dynabeads mRNA Direct Kit (Thermo Fisher Scientific, Waltham, MA, USA) [18]. Three biological pools were made for each breed of pig. In the commercial cross-bred pigs, three pigs, two pigs, and two pigs were pooled. In the Large Black pig group, three, three, and two pigs were pooled. The RNA fragmentation, library prep, and adapter ligation were performed using the NEBNext Ultra Directional Library Prep kit for for Illumina (New England Biolabs, Ipswich, MA, USA). Library size and quality were assessed using the High Sensitivity DNA Analysis Kit for the Agilent Bioanalyzer (Agilent, Santa Clara, CA, USA) and library concentration was determined using the Qubit dsDNA HS Assay Kit (Thermo Fisher Scientific). Single-read 75-bp sequencing of libraries were performed using a NextSeq500 (Illumina, San Diego, CA, USA). The FastQC app in BaseSpace was used to assess read quality and the FASTQ Toolkit was used for adapter trimming, base trimming low quality reads at the $3^{\prime}$ end, and filtering using a minimum mean quality score of 30 (Illumina) (http:/ / basespace.illumina.com/apps/). Alignment was performed using the Star Alignment app in BaseSpace and aligned to the pig genome (sus scrofa 11.1_v91) (Table S1 and Figure S1) [19]. The resulting Bam files were uploaded into SeqMonk (v.1.37.1, http:/ /www.bioinformatics.babraham.ac.uk/projects/seqmonk/) for differential expression analysis using the EdgeR package in SeqMonk $(p<0.05$ after FD correction) [20]. The lists of differentially expressed genes were further analyzed for GO 
of biological function enrichment using the Database for Annotation, Visualization and Integrated Discovery (DAVID) tool [21,22].

\section{Results and Discussion}

\subsection{Growth Performance and Carcass Measurements}

The growth performances in terms of initial and final body weight and the quality of carcass are presented in Table 2. The initial body weights of CP and BP groups showed no significant differences $(p>0.05)$. However, the $\mathrm{CP}$ group had higher final body weight $(p<0.05)$, ADG $(p<0.05)$ and hot carcass weight $(p<0.01)$ compared with the BP group. According to Bessa et al. [23], the fat deposition of the Large Black pig is higher than the crossbreed pig. Correspondingly, the BP group showed a strong fat deposition ability with significantly higher $(p<0.01)$ back fat thickness values compared to $\mathrm{CP}$.

Table 2. Effect of breeds on the carcass characteristics.

\begin{tabular}{cccccc}
\hline Parameters & $\mathbf{C P}^{\mathbf{a}}$ & \multicolumn{3}{c}{ BP } & $p$-Value \\
\hline & Mean & sd & Mean & sd \\
\hline Initial body weight $(\mathrm{kg})$ & 18.82 & 1.41 & 23.31 & 1.93 & 0.1097 \\
Final body weight $(\mathrm{kg})$ & 130.04 & 8.16 & 121.17 & 2.80 & 0.0341 \\
$\mathrm{ADG}^{\mathrm{b}}(\mathrm{kg})$ & 1.10 & 0.05 & 0.91 & 0.01 & 0.0452 \\
Hot carcass weight $(\mathrm{kg})_{\text {Back fat thickness }(\mathrm{cm})}$ & 0.77 .95 & 9.81 & 63.63 & 0.95 & 0.0060 \\
\hline
\end{tabular}

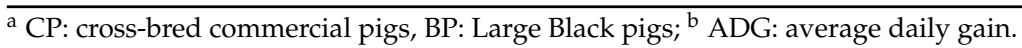

\subsection{Meat Quality}

Meat quality traits of CP and BP groups are summarized in Table 3. Drip loss is one of the important characteristics of water holding capacity (WHC). There was no significant difference shown in drip loss between $\mathrm{CP}$ and $\mathrm{BP}(p>0.05)$. For the meat color, $\mathrm{L}^{*}$ indicates lightness, $\mathrm{a}^{*}$ relates to the red/green coordinate, $\mathrm{b}^{*}$ shows the yellow/blue coordinate, $\mathrm{C}^{*}$ means chroma, and $h$ is the hue angle [24]. There were no significant differences in $L^{*}, b^{*}$ and $C^{*}$ between these two groups $(p>0.05)$. In contrast, the $\mathrm{a}^{*}$ value of $\mathrm{CP}$ was higher $(p<0.01)$ than BP, but the $h$ value of BP was higher $(p<0.05)$ than CP.

Table 3. Effect of breeds on the meat quality of pork (longissimus dorsi).

\begin{tabular}{|c|c|c|c|c|c|}
\hline \multirow[t]{2}{*}{ Parameters } & \multirow{2}{*}{$\frac{\mathbf{C P}^{\mathbf{a}}}{\text { Mean }}$} & \multicolumn{3}{|c|}{ BP } & \multirow[t]{2}{*}{$p$-Value } \\
\hline & & sd & Mean & sd & \\
\hline Drip loss (\%) & 3.38 & 0.11 & 3.41 & 0.17 & 0.9571 \\
\hline$L^{* b}$ & 57.78 & 4.52 & 60.24 & 2.43 & 0.3072 \\
\hline$a^{*}$ & 16.72 & 1.73 & 14.58 & 1.09 & 0.0063 \\
\hline$b^{*}$ & 14.31 & 1.68 & 13.73 & 0.67 & 0.4192 \\
\hline$C^{*}$ & 22.02 & 2.28 & 19.99 & 1.09 & 0.0951 \\
\hline $\mathrm{h}$ & 40.49 & 2.13 & 43.47 & 1.64 & 0.0176 \\
\hline \multicolumn{6}{|c|}{ Proximal composition: } \\
\hline Total fat $(\%)$ & 6.24 & 1.53 & 10.02 & 1.20 & 0.0431 \\
\hline
\end{tabular}

a CP: cross-bred commercial pigs, BP: Large Black pigs; ${ }^{b} \mathrm{~L}^{*}$ : lightness; $\mathrm{a}^{*}$ : red-green; $\mathrm{b}^{*}$ : yellow-blue; $\mathrm{C}^{*}$ bright-dull; h: hue.

The IMF content of these two breeds was significantly different $(p<0.05)$, meaning that the IMF of BP is higher than that of CP pigs. However, the different fat content did not affect the drip loss. Watanabe et al. [25] pointed out that pork IMF content was not correlated with drip loss, and our result had the same trend. The fat content of $\mathrm{CP}$ is similar with other reports about white pig breeds [26,27], and the fat deposition of BP is much higher than these commercial pigs. Research comparing Iberian pigs and commercial crossbred pigs showed a strong correlation between IMF and backfat thickness [28]. Our data 
showed higher IMF and backfat deposition in the Large Black pigs, which demonstrated the similar fat deposition patterns in local native pigs which is different from commercial cross-bred pigs.

\subsection{Oxygen Consumption}

The OCR is positively correlated with mitochondrial concentration [29]. In addition, mitochondria present in the postmortem muscle can remain active and impact on the meat color through oxygen consumption [30]. The OCR of BP was higher than that in $\mathrm{CP}$ $(p<0.01$; Figure 1). It was reported that muscles with more $\beta$-red fibers tend to have higher OCR than muscles with more $\alpha$-white fibers [31]. However, the relationship between oxygen consumption and meat quality needs to be further evaluated to understand color variations between the two groups of pigs. A study of the muscle fiber type of Korean native pig reported a higher proportion of type I muscle fibers than that in commercial cross-bred pigs [32]. The type I slow twitch fiber has a higher mitochondria content for oxidative phosphorylation. This report was consistent with what we found; the local native pigs had higher mitochondrial metabolism correlated with the higher content of type I muscle fiber.

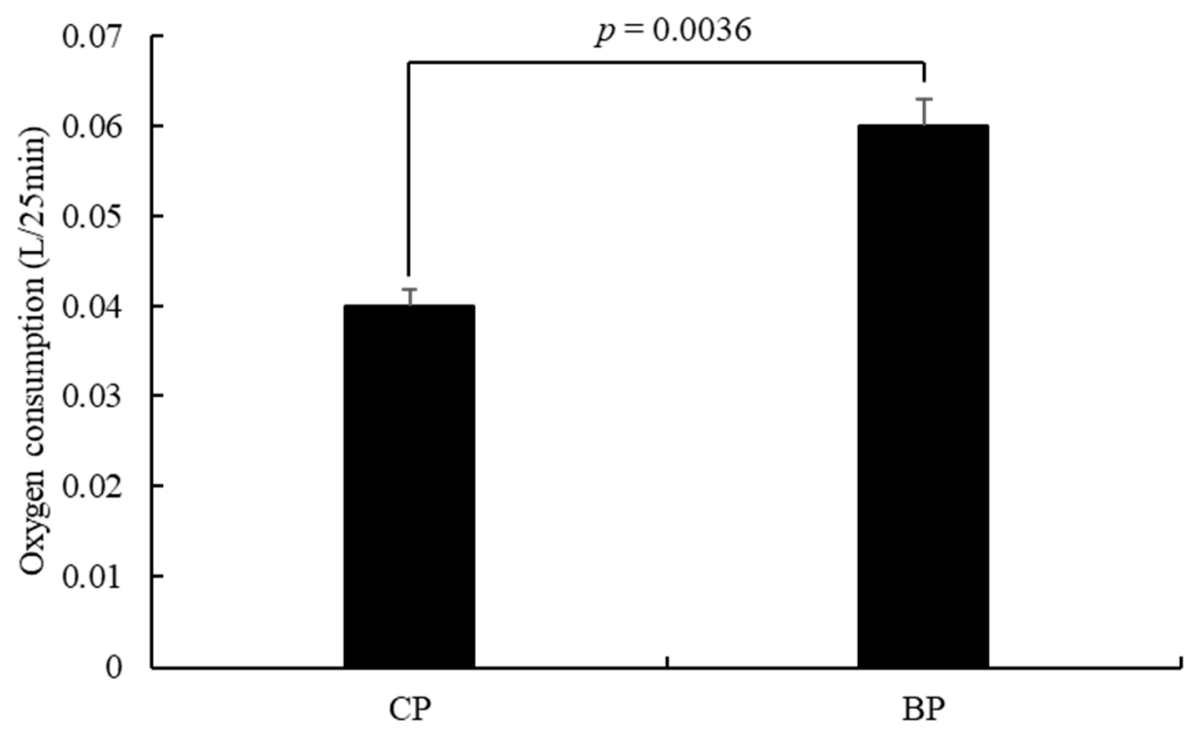

Figure 1. Effect of breeds on the oxygen consumption (longissimus dorsi) (CP: cross-bred commercial pigs; BP: Large Black pigs).

\subsection{Myoglobin Calculation}

The color of meat after slaughter is primarily affected by myoglobin, which is a sarcoplasmic heme protein [33]. This protein can exist as deoxymyoglobin (DMb), oxymyoglobin $(\mathrm{OMb})$, and metmyoglobin $(\mathrm{MMb})$ in fresh meat [30]. Our results showed differences in the percentage of myoglobin between $\mathrm{CP}$ and $\mathrm{BP}$ breeds (Figure 2). The MMb (metmyoglobin) percentage of $\mathrm{CP}$ was higher $(p<0.05)$ than $\mathrm{BP}$, but there were no significant differences between $\mathrm{CP}$ and $\mathrm{BP}$ in $\mathrm{DMb}$ (deoxymyoglobin) and $\mathrm{OMb}$ (oxymyoglobin). The chemistry and functions of myoglobin in live muscles and meat may be different, but the functions of myoglobin as the oxygen binder and oxygen deliverer to maintain the physiological functions of mitochondria continues normally [34]. In addition, myoglobin is related to red meat color, which is a main meat purchasing factor for consumers [35].

\subsection{Fatty Acid Composition}

The fatty acid compositions of LD muscles from CP and BP breeds are listed in Table 4 . There was a significant fatty acid composition difference between $\mathrm{CP}$ and $\mathrm{BP}$ in most comparisons $(p<0.05)$. The total polyunsaturated fatty acid contents of $\mathrm{CP}$ were higher $(p<0.05)$ than BP, such as C18:2n-6, C18:3n-3, C20:2, C20:3n-6, C20:4n-6, and C22:5. However, BP had 
higher total monounsaturated fatty acid content along with higher C:10, C:20, C18:1, and C20:0 contents compared to CP. The overall saturated and unsaturated fatty acids contents of $\mathrm{CP}$ and BP were not significantly different $(p>0.05)$.

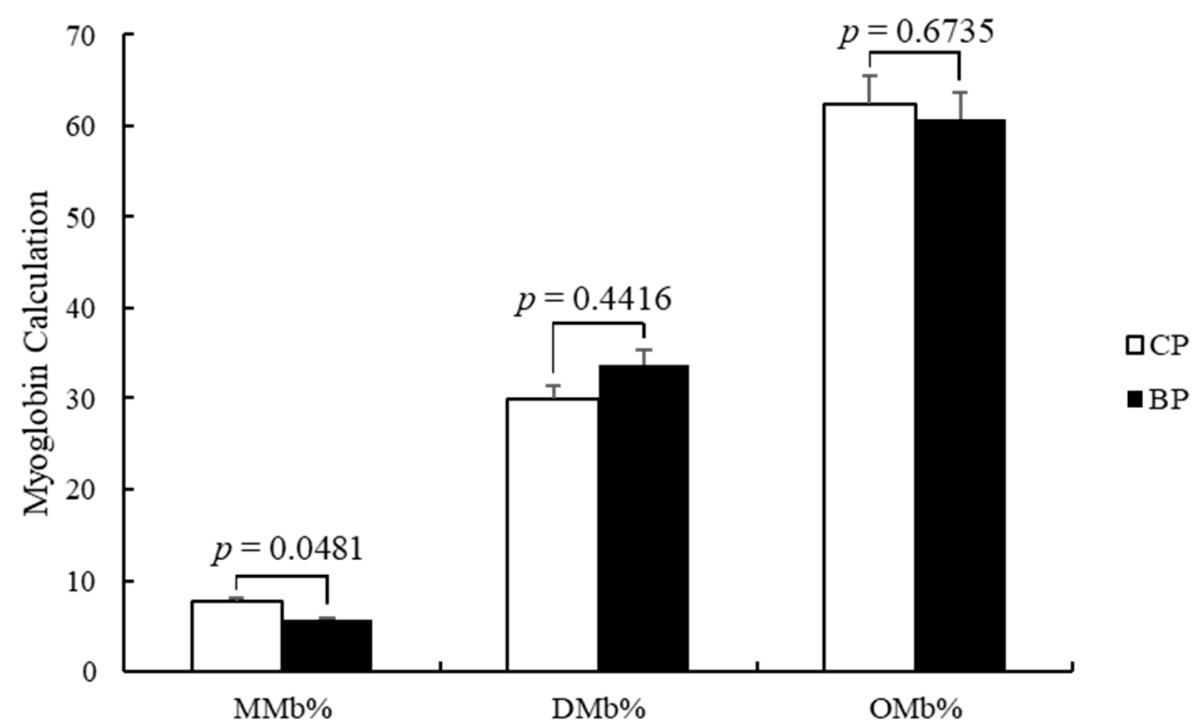

Figure 2. Effect of breeds on the myoglobin calculation (longissimus dorsi) (CP: cross-bred commercial pigs, BP: Large Black pigs; MMb: Metmyoglobin, DMb: Deoxymyoglobin, OMb: Oxymyoglobin).

Table 4. Effect of breeds on the fatty acid profile of intramuscular fat (Longissimus dorsi).

\begin{tabular}{cccccc}
\hline & CP $^{\mathbf{a}}$ & \multicolumn{5}{c}{ BP } & p-Value \\
\hline & Mean & sd & Mean & sd & \\
\hline C10:0 & 0.08 & 0.01 & 0.10 & 0.01 & 0.0074 \\
C12:0 & 0.06 & 0.01 & 0.07 & 0.01 & 0.2895 \\
C14:0 & 1.14 & 0.17 & 1.20 & 0.08 & 0.5063 \\
C16:0 & 23.76 & 0.66 & 24.21 & 0.73 & 0.3495 \\
C16:1 & 3.06 & 0.46 & 3.32 & 2.41 & 0.2189 \\
C17:0 & 0.23 & 0.03 & 0.24 & 0.02 & 0.5706 \\
C18:0 & 11.74 & 0.79 & 11.95 & 0.73 & 0.4128 \\
C18:1 & 41.81 & 3.20 & 46.21 & 1.05 & 0.0153 \\
C18:2n-6 & 12.67 & 2.74 & 8.74 & 1.40 & 0.0352 \\
C18:3n-3 & 0.27 & 0.02 & 0.23 & 0.04 & 0.0496 \\
C20:0 & 0.13 & 0.01 & 0.19 & 0.02 & 0.0013 \\
C20:1 & 0.51 & 0.10 & 0.70 & 0.07 & 0.0007 \\
C20:2 & 0.29 & 0.04 & 0.23 & 0.02 & 0.0061 \\
C20:3n-6 & 0.35 & 0.11 & 0.22 & 0.05 & 0.0085 \\
C20:4n-6 & 2.82 & 0.87 & 1.53 & 0.48 & 0.0032 \\
C22:5 & 0.28 & 0.09 & 0.14 & 0.04 & 0.0162 \\
SFA b & 37.07 & 1.09 & 37.96 & 1.40 & 0.7946 \\
UFA & 62.04 & 1.05 & 61.25 & 1.34 & 0.5138 \\
MUFA & 45.32 & 3.61 & 50.18 & 1.21 & 0.0006 \\
PUFA & 3.75 & 1.06 & 2.11 & 0.55 & 0.0004 \\
n6/n3 & 27.59 & 3.63 & 28.35 & 3.08 & 0.0901 \\
\hline
\end{tabular}

a CP: cross-bred commercial pigs, BP: Large Black pigs; ${ }^{\text {b SFA: saturated fatty acid; UFA: unsaturated fatty acid }}$ MUFA: monounsaturated fatty acid; PUFA: polyunsaturated fatty acid; $n 6 / n 3$ : the ratio of $n-6$ fatty acids to n-3 fatty acids.

The fatty acid composition has a strong relationship with the IMF content and backfat thickness [36]. It was reported that intramuscular and backfat would increase the percentage of saturated, especially monounsaturated fatty acids, and the data of our experiment are in agreement with these findings [37]. The fatty acid composition variations in $\mathrm{CP}$ and 
$\mathrm{BP}$ are probably attributed to the difference in fat deposition between these two groups of pigs. The SFA level of intramuscular fat in the loin has negative correlations with meat sensory qualities, such as acid flavor [38]. However, there were no significant differences of SFA between BP and CP. It was reported that monounsaturated fatty acids are the major fatty acid component in the Mediterranean diet, of which benefits include lowering the risk of cardiovascular disease [39]. The IMF content in BP LD muscle is about 1.6 times higher than CP $(10.02 \pm 1.20: 6.24 \pm 1.53, p<0.05$. Table 2$)$, which might indicate that BP pork products have more health value with a higher content of monounsaturated fatty acids.

There are limitations in the results of growth performance, meat color, and fatty acid profile due to the small sample numbers. These data may not reflect the obtained results to a breed-wide interpretation. Future study will utilize a bigger range of the sample numbers.

\subsection{Differentially Expressed Gene Analysis}

High-throughput sequencing is a powerful way to identify the differences in gene expression, which was used in the study of different breeds to compare the difference of gene expressions related with meat quality [40]. By comparing LD muscle transcriptome differences between BP and CP, we found that there was a total of 363 differentially expressed genes (Table S2) found between these two breeds, in which 201 were highly differentially expressed ( $\log 2$ fold change $\geq 1$ or $\leq-1 ; p<0.05)$. Full details of gene name, description, identification, and fold change (FC) are reported in the Table S2. Compared with CP, BP had 75 up-regulated and 126 down-regulated genes (Figure 3). The functional category of these 201 differentially expressed genes, of which 75 were highly expressed in BP and 126 were highly expressed in $\mathrm{CP}$, were determined by querying associated gene ontologies, and they were classified into biological process, cellular component, and molecular function (Figures 4-6), by using DAVID bioinformatic resources. GO analysis showed the functional enrichment of these differentially expressed genes, and the different genes expressed may be the cause of diversities in carcass characteristics and meat quality between these two groups of pigs. For biological processes, five highly expressed genes in BP were related with fat cell differentiation (Figure 4). This might have led to a higher IMF content of LD muscle in BP, compared with CP. In molecular functions, we found that six genes, which were highly expressed in $\mathrm{CP}$, were responsible for oxidoreductase activity, and these genes' higher expression may cause the different OCR of the LD muscle between $\mathrm{BP}$ and $\mathrm{CP}$.

\subsection{Gene Expression}

In order to verify our RNA-seq expression profile data, we utilized real-time quantitative RT-PCR to determine eight genes related to lipid deposition or metabolism, and the results (Figure 7) partly validated the transcriptome profiles of RNA-seq. Results are presented as numerical relative gene expression values (using GAPDH as a housekeeping calibrator). The expression of lipid and energy metabolic related genes (TKTL2, ACBD7, $A C S L 6$, and FOS ) were higher in CP than in $\mathrm{BP}(p<0.05)$. In addition, $\mathrm{CP}$ exhibited higher $(p<0.05)$ mRNA abundance of the THRSP gene, which is related to medium-length fatty acid chains [41]. However, the gene expression of SLPI which is involved in epithelial immunity was higher in BP $(p<0.05)$ and is consistent with the characteristic of stronger environmental tolerance in BP as a native pig breed compared to CP [42]. The genes related to energy metabolism and unsaturated fatty acids composition (SLC26A7 and FADS1) were more highly expressed in CP. Pigs of different breeds always have different conditions of metabolism and lipid deposition. SLC26A7 is strongly related to energy metabolism [43]. TKTL2 is related to lipid transport and metabolism, and the genetic distance increased from local pig breeds after selective seep caused by the selection of energy-rich pork production [44]. $A C B D 7$ is one of the gene families related to intracellular lipid-binding proteins [45]. The FADS1 gene is associated with the unsaturated fatty acid composition [46]. It has been reported that ACSL6 contributes to lipid synthesis [47]. 
Reiner et al. [48] reported that FOS is an important gene correlated with skeletal muscle fiber and metabolism. Above all, the differential of gene expression related to lipid and energy metabolism might cause the different fat deposition ability of $\mathrm{CP}$ and $\mathrm{BP}$.

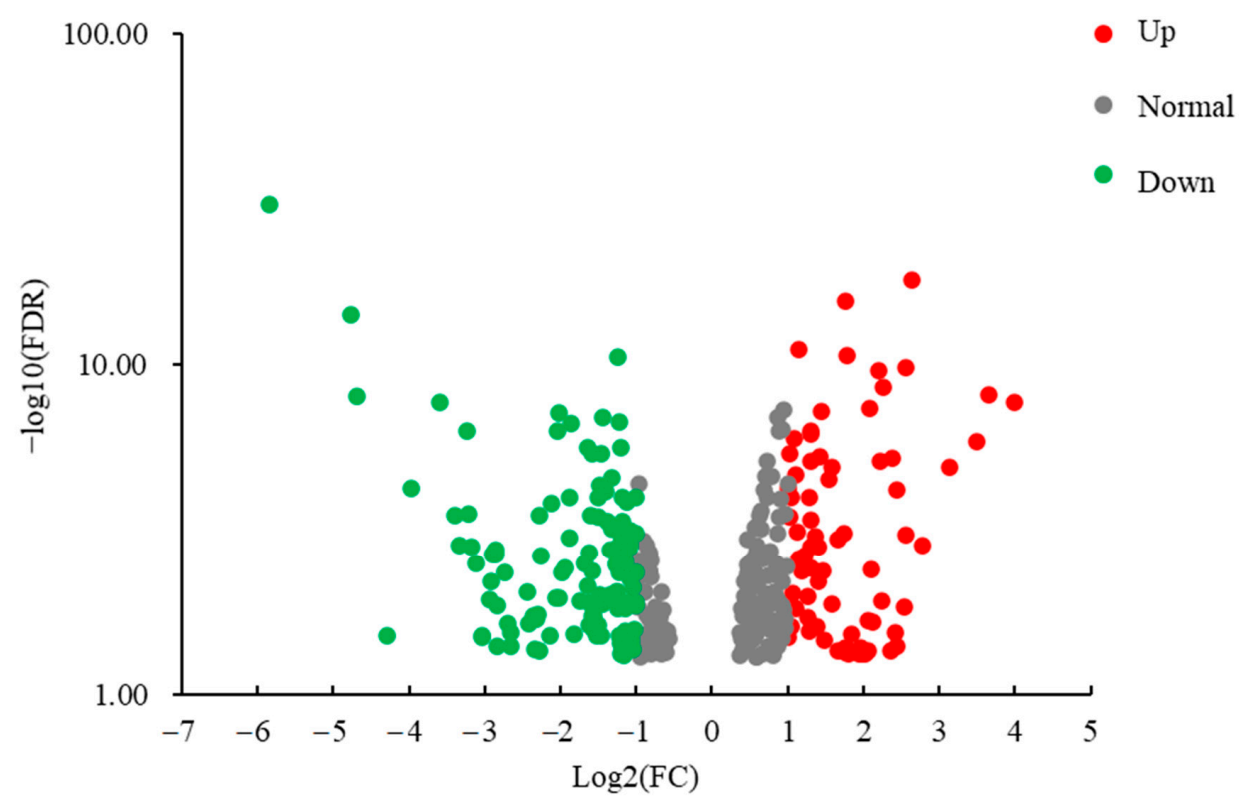

Figure 3. Volcano figure of RNA-seq (BP vs. CP; CP: cross-bred commercial pigs, BP: Large Black pigs; Up: up-regulated in BP compared with CP; Normal: no significant differences; Down: down-regulated in BP compared with CP).

A Number of Biological Process Pathways Enriched in BP

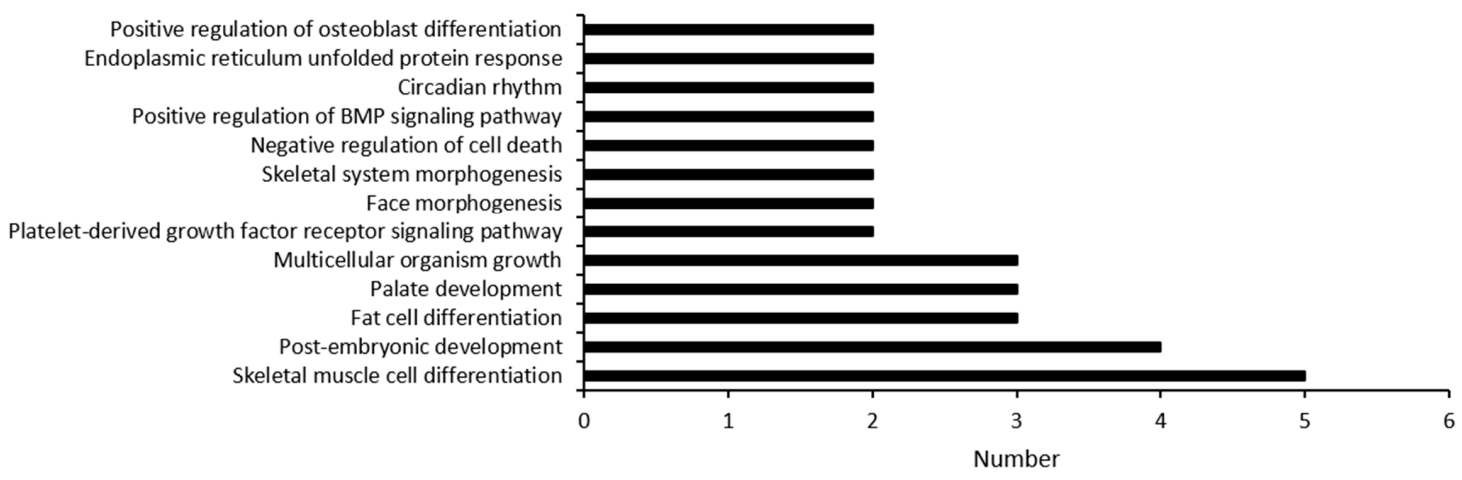

B Number of Biological Process Pathways Enriched in CP

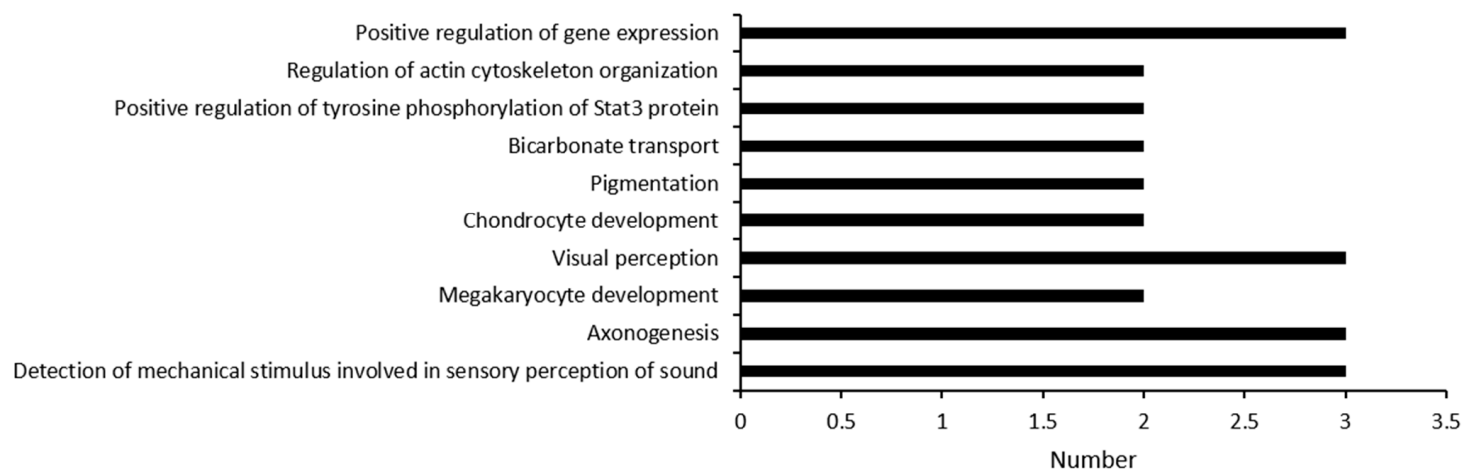

Figure 4. Gene ontology (GO) analysis of differentially expressed genes highly expressed in BP (A) and CP (B). The identified differentially expressed genes were classified into biological processes. The numbers of genes in the GO term is shown above (BP vs. CP; CP: cross-bred commercial pigs, BP: Large Black pigs). 
A

$$
\text { Number of Cellular Component Pathways }
$$

Enriched in BP

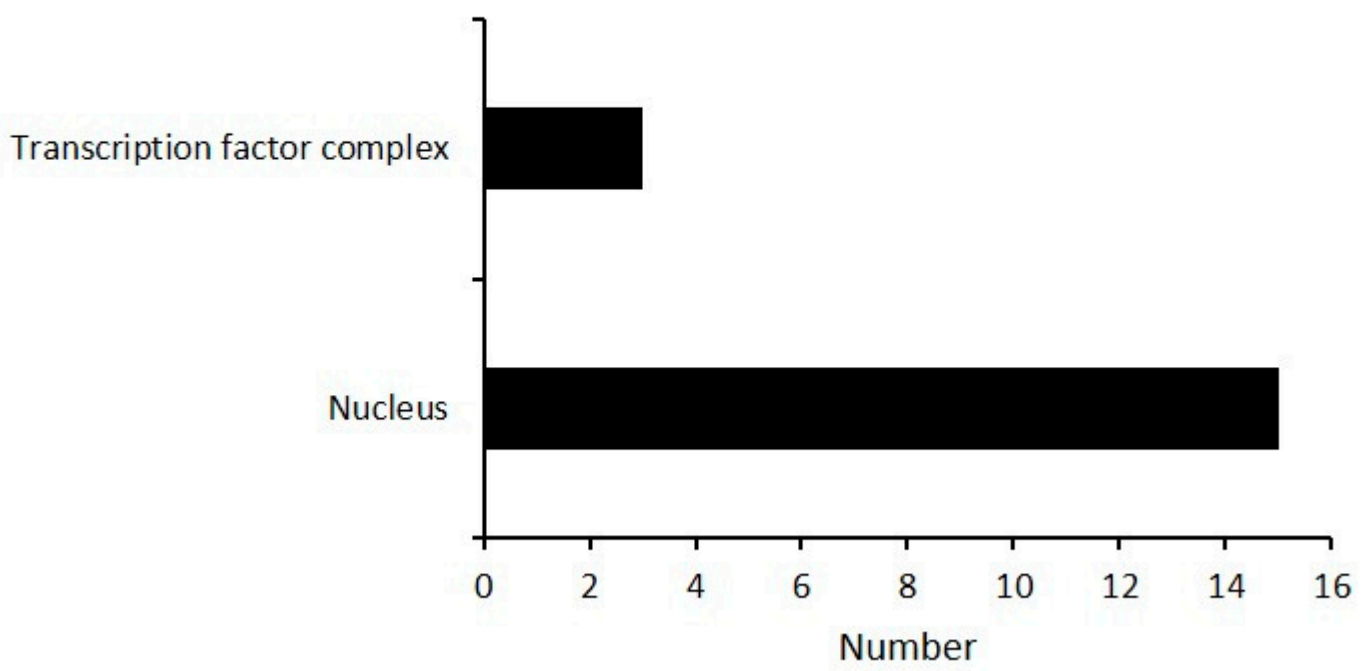

B

\section{Number of Cellular Component Pathways Enriched in $\mathrm{CP}$}

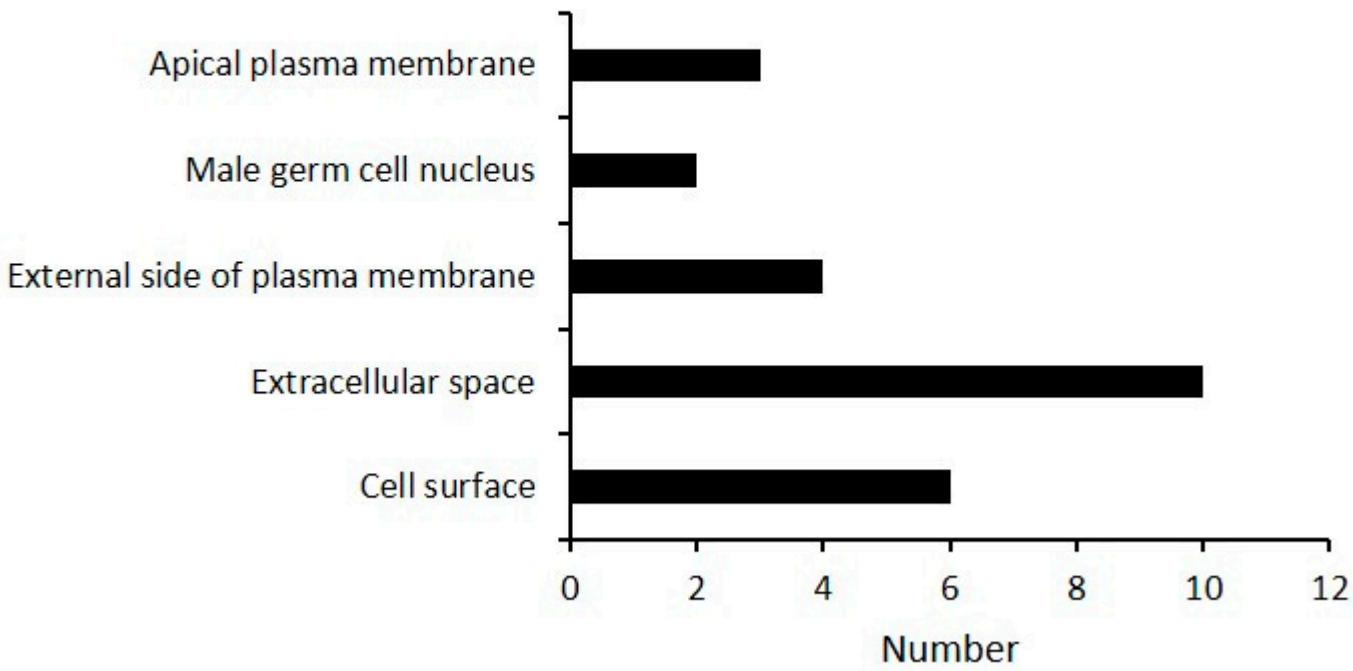

Figure 5. Gene ontology (GO) analysis of differentially expressed genes highly expressed in BP (A) and CP (B). The identified differentially expressed genes were classified into cellular components. The number of genes in the GO term is shown above (BP vs. CP; CP: cross-bred commercial pigs, BP: Large Black pigs). 
A

\section{Number of Molecular Function Pathways \\ Enriched in BP}

ranscriptional activator activity

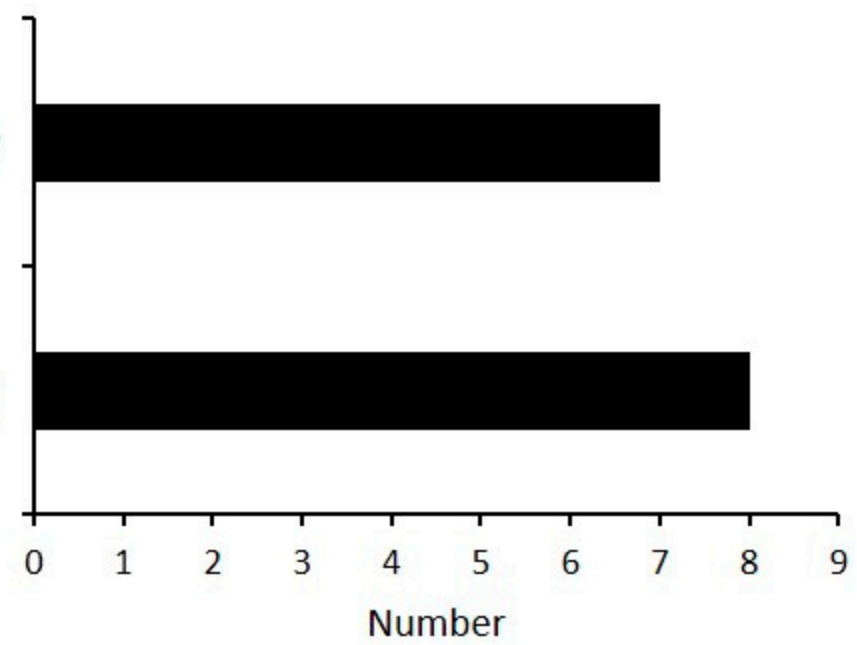

B

\section{Number of Molecular Function Pathways Enriched in CP}

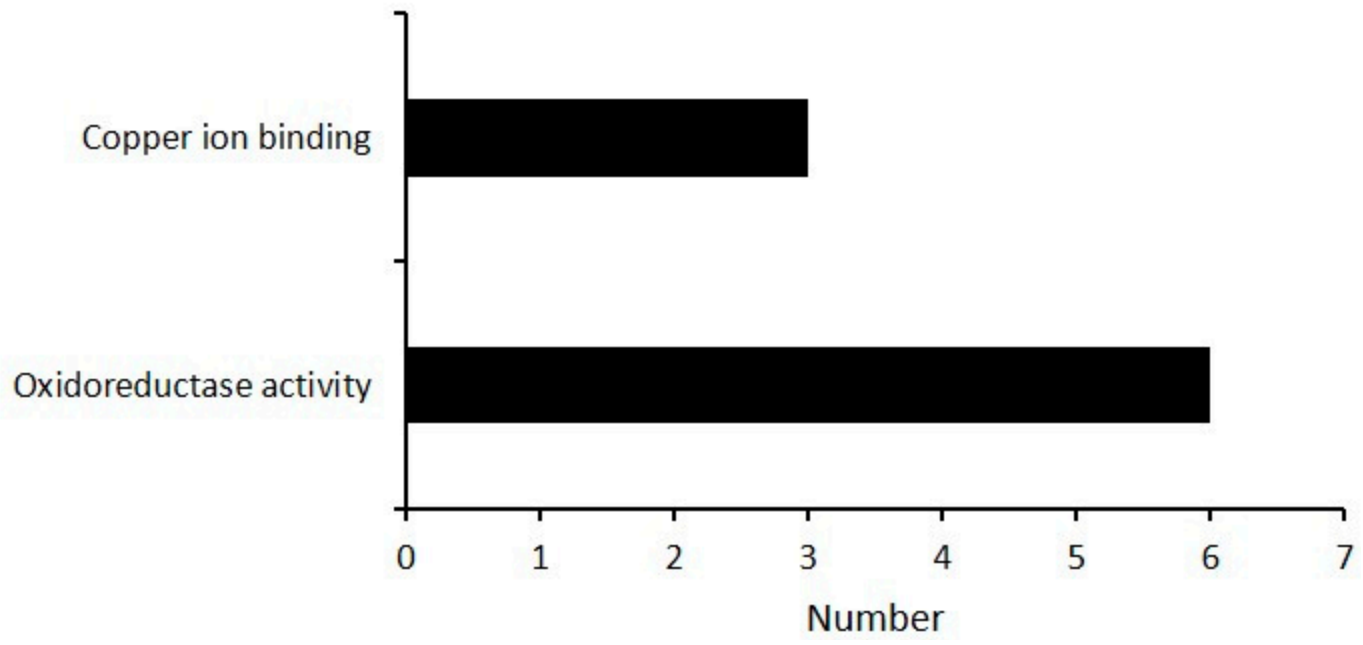

Figure 6. Gene ontology (GO) analysis of differentially expressed genes highly expressed in BP (A) and CP (B). The identified differentially expressed genes were classified into molecular functions. The number of genes in the GO term is shown above (BP vs. CP; CP: cross-bred commercial pigs, BP: Large Black pigs). 

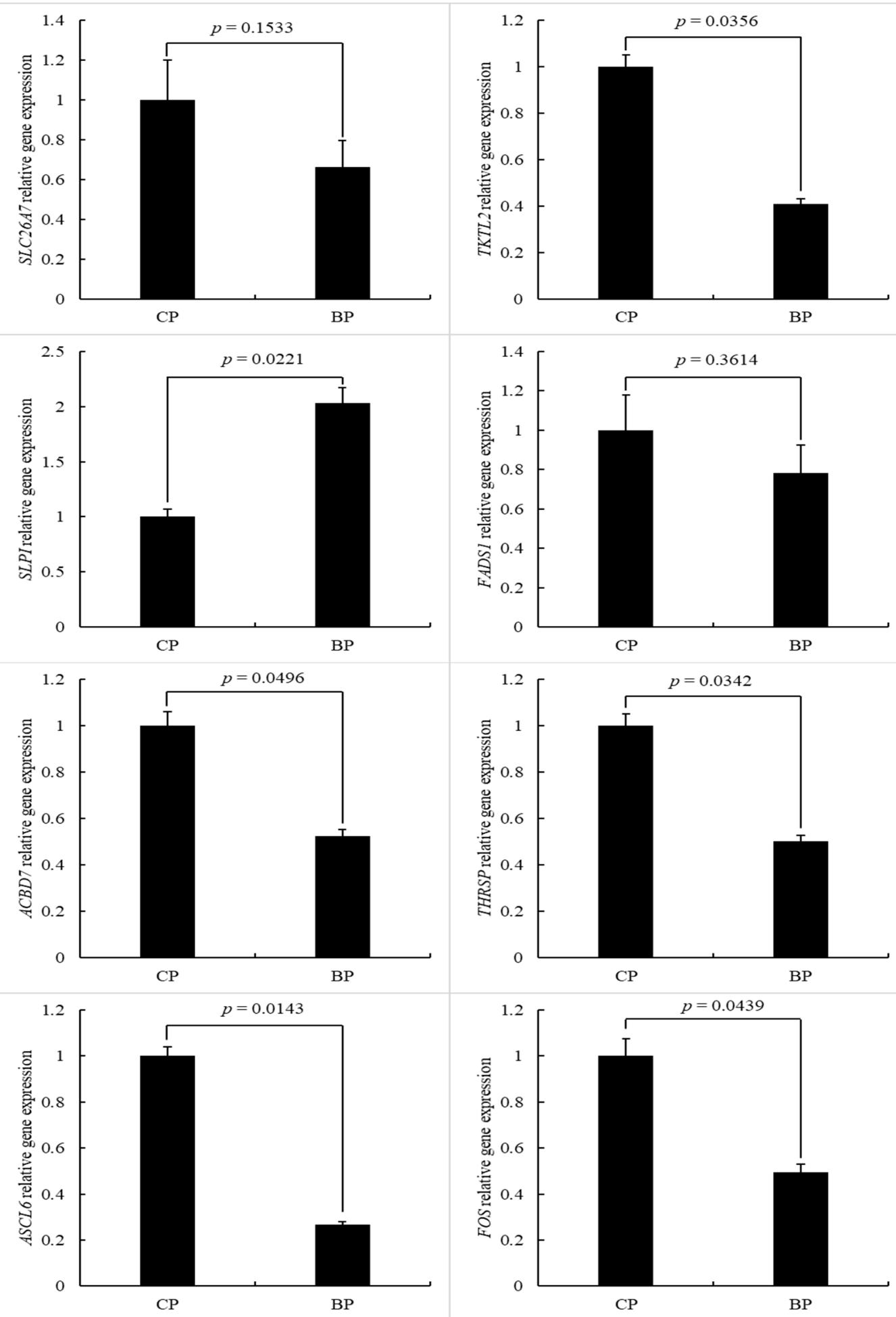

Figure 7. Effect of breeds on the relative gene expression (BP vs. CP; CP: cross-bred commercial pigs, BP: Large Black pigs).

\section{Conclusions}

In conclusion, the growth performance of $\mathrm{CP}$ was higher than $\mathrm{BP}$, but the intramuscular fat content of $\mathrm{BP}$ was higher than $\mathrm{CP}$, which indicates higher meat quality in the BP group. The meat oxygen consumption rate of $\mathrm{LD}$ muscle in the BP group was also high; therefore, the Large Black pigs have higher metabolic rate and possibly more type I muscle fiber. The RNA-seq and gene expression data qualitatively and quantitatively proved that there were 
differences in intramuscular transcriptome profiles of these two groups of pigs. Comparing $\mathrm{BP}$ with CP, 201 significantly differentially expressed genes in the LD muscle were identified. The analysis of the genes between the two groups of pigs may provide a novel strategy in swine genetic selection for both high growth performance and high meat quality, especially concerning marbling and flavor.

Supplementary Materials: The following are available online at https:/ /www.mdpi.com/2076-2 615/11/1/200/s1, Table S1: Alignment information. Pig_W: Cross-bred commercial pigs, Pig_B: Large Black pigs, Table S2: Raw data of RNA sequencing. Pig_W: Cross-bred commercial pigs, Pig_B: Large Black pigs, Figure S1: Alignment distribution plots. Percentage bases aligned to region. Pig_W: Cross-bred commercial pigs, Pig_B: Large Black pigs.

Author Contributions: Y.W., S.S., J.C. and J.A. analyzed the data. Y.W., S.S., P.M., J.A. and Y.H. took measurements and collected samples. K.T. conducted RNA sequencing and functional analysis. Y.W., P.M. and S.S. wrote the manuscript. All authors have read and agreed to the published version of the manuscript.

Funding: This work was supported by the USDA National Institute of Food and Agriculture, Hatch Project Accession No.: 1010063.

Institutional Review Board Statement: The study was conducted according to the guidelines of the Declaration of Helsinki, and approved by the Ethics Committee of the University of Arkansas (protocol code 18000, approved on 12th October 2017)

Data Availability Statement: The datasets used and/or analyzed during the current study are available from the corresponding author on reasonable request.

Conflicts of Interest: The authors declare no conflict of interest.

\section{References}

1. Dransfield, E.; Ngapo, T.; Nielsen, N.A.; Bredahl, L.; Sjödén, P.-O.; Magnusson, M.; Campo, M.; Nute, G. Consumer choice and suggested price for pork as influenced by its appearance, taste and information concerning country of origin and organic pig production. Meat Sci. 2005, 69, 61-70. [CrossRef] [PubMed]

2. Rosenvold, K.; Andersen, H.J.J.M.s. Factors of significance for pork quality-A review. Meat Sci. 2003, 64, 219-237. [CrossRef]

3. Bonneau, M.; Lebret, B.J.M.s. Production systems and influence on eating quality of pork. Meat Sci. 2010, 84, 293-300. [CrossRef] [PubMed]

4. Herrera-Mendez, C.H.; Becila, S.; Boudjellal, A.; Ouali, A. Meat ageing: Reconsideration of the current concept. Trends Food Sci. Technol. 2006, 17, 394-405. [CrossRef]

5. Ekarius, C. Storey's Illustrated Breed Guide to Sheep, Goats, Cattle, and Pigs; Storey Publishing LCC: North Adams, MA, USA, 2008.

6. Dohner, J.V. The Encyclopedia of Historic and Endangered Livestock and Poultry Breeds; Yale University Press: London, UK, 2001.

7. Freeman, T.C.; Ivens, A.; Baillie, J.K.; Beraldi, D.; Barnett, M.W.; Dorward, D.; Downing, A.; Fairbairn, L.; Kapetanovic, R.; Raza, S. A gene expression atlas of the domestic pig. BMC Biol. 2012, 10, 90. [CrossRef]

8. Bonnet, A.; Bevilacqua, C.; Benne, F.; Bodin, L.; Cotinot, C.; Liaubet, L.; Sancristobal, M.; Sarry, J.; Terenina, E.; Martin, P. Transcriptome profiling of sheep granulosa cells and oocytes during early follicular development obtained by laser capture microdissection. BMC Genom. 2011, 12, 417. [CrossRef]

9. Martin, J.A.; Wang, Z. Next-generation transcriptome assembly. Nat. Rev. Genet. 2011, 12, 671. [CrossRef]

10. Ozsolak, F.; Milos, P.M. RNA sequencing: Advances, challenges and opportunities. Nat. Rev. Genet. 2011, 12, 87-98. [CrossRef]

11. National Pork Board and EMI Analytics. Typical Market Pig Today. Available online: https://www.pork.org/facts/stats/ consumption-and-expenditures/typical-market-pig-today/ (accessed on 15 August 2017).

12. Sukhija, P.S.; Palmquist, D. Rapid method for determination of total fatty acid content and composition of feedstuffs and feces. $J$. Agric. Food Chem. 1988, 36, 1202-1206. [CrossRef]

13. Christensen, L.B. Drip loss sampling in porcine m. longissimus dorsi. Meat Sci. 2003, 63, 469-477. [CrossRef]

14. O'fallon, J.; Busboom, J.; Nelson, M.; Gaskins, C. A direct method for fatty acid methyl ester synthesis: Application to wet meat tissues, oils, and feedstuffs. J. Anim. Sci. 2007, 85, 1511-1521. [CrossRef] [PubMed]

15. Zou, T.; Wang, B.; Yang, Q.; de Avila, J.M.; Zhu, M.J.; You, J.; Chen, D.; Du, M. Raspberry promotes brown and beige adipocyte development in mice fed high-fat diet through activation of AMP-activated protein kinase (AMPK) alpha1. J. Nutr. Biochem. 2018, 55, 157-164. [CrossRef] [PubMed]

16. Li, Q.; Domig, K.J.; Ettle, T.; Windisch, W.; Mair, C.; Schedle, K. Evaluation of potential reference genes for relative quantification by RT-qPCR in different porcine tissues derived from feeding studies. Int. J. Mol. Sci. 2011, 12, 1727-1734. [CrossRef] [PubMed]

17. Huang, Y.; Yan, X.; Zhao, J.X.; Zhu, M.J.; McCormick, R.J.; Ford, S.P.; Nathanielsz, P.W.; Ren, J.; Du, M. Maternal obesity induces fibrosis in fetal myocardium of sheep. Am. J. Physiol. Endocrinol. Metab. 2010, 299, E968-E975. [CrossRef] [PubMed] 
18. Saben, J.; Kang, P.; Zhong, Y.; Thakali, K.M.; Gomez-Acevedo, H.; Borengasser, S.J.; Andres, A.; Badger, T.M.; Shankar, K. RNA-seq analysis of the rat placentation site reveals maternal obesity-associated changes in placental and offspring thyroid hormone signaling. Placenta 2014, 35, 1013-1020. [CrossRef] [PubMed]

19. Dobin, A.; Davis, C.A.; Schlesinger, F.; Drenkow, J.; Zaleski, C.; Jha, S.; Gingeras, T.R. STAR: Ultrafast universal RNA-seq aligner. Bioinformatics 2013, 29, 15-21. [CrossRef]

20. Robinson, M.D.; McCarthy, D.J.; Smyth, G.K. edgeR: A Bioconductor package for differential expression analysis of digital gene expression data. Bioinformatics 2010, 26, 139-140. [CrossRef]

21. Sherman, B.T.; Lempicki, R.A. Systematic and integrative analysis of large gene lists using DAVID bioinformatics resources. Nat. Protoc. 2009, 4, 44-57.

22. Dennis, G.; Sherman, B.T.; Hosack, D.A.; Yang, J.; Gao, W.; Lane, H.C.; Lempicki, R.A. DAVID: Database for annotation, visualization, and integrated discovery. Nat. Protoco. 2003, 4, 44.

23. Bessa, R.J.B.; Hughes, R.A.; Jeronimo, E.; Moreira, O.C.; Prates, J.A.M.; Doran, O. Effect of pig breed and dietary protein level on selected fatty acids and stearoyl-coenzyme A desaturase protein expression in longissimus muscle and subcutaneous fat. J. Anim. Sci. 2013, 91, 4540-4546. [CrossRef]

24. Eagerman, B.; Clydesdale, F.; Francis, F. Determination of fresh meat color by objective methods. J. Food Sci. 1977, 42, 707-710. [CrossRef]

25. Watanabe, G.; Motoyama, M.; Nakajima, I.; Sasaki, K. Relationship between water-holding capacity and intramuscular fat content in Japanese commercial pork loin. Asian Australas J. Anim. Sci. 2018, 31, 914-918. [CrossRef] [PubMed]

26. Lo, L.; McLaren, D.; McKeith, F.; Fernando, R.; Novakofski, J. Genetic analyses of growth, real-time ultrasound, carcass, and pork quality traits in Duroc and Landrace pigs: I. Breed effects. J. Anim. Sci. 1992, 70, 2373-2386. [CrossRef] [PubMed]

27. De Vries, A.; Van der Wal, P.; Long, T.; Eikelenboom, G.; Merks, J. Genetic parameters of pork quality and production traits in Yorkshire populations. Livest. Prod. Sci. 1994, 40, 277-289. [CrossRef]

28. Bressan, M.C.; Almeida, J.; Santos Silva, J.; Bettencourt, C.; Francisco, A.; Gama, L.T. Carcass characteristics and fat depots in Iberian and F Large White $x$ Landrace pigs intensively finished or raised outdoors in oak-tree forests. J. Anim. Sci. 2016, 94, 2592-2602. [CrossRef]

29. Tang, J.; Faustman, C.; Hoagland, T.A.; Mancini, R.A.; Seyfert, M.; Hunt, M.C.; Chemistry, F. Postmortem oxygen consumption by mitochondria and its effects on myoglobin form and stability. J. Agric. Food Chem. 2005, 53, 1223-1230. [CrossRef]

30. Ramanathan, R.; Mancini, R.A.J.M.; Biology, M. Role of Mitochondria in Beef Color: A Review. Meat Muscle Biol. 2018, 2, 309-320. [CrossRef]

31. Hunt, M.; Hedrick, H.J.J.o.F.S. Profile of fiber types and related properties of five bovine muscles. J. Food Sci. 1977, $42,513-517$. [CrossRef]

32. Cho, I.C.; Park, H.B.; Ahn, J.S.; Han, S.H.; Lee, J.B.; Lim, H.T.; Yoo, C.K.; Jung, E.J.; Kim, D.H.; Sun, W.S.; et al. A functional regulatory variant of MYH3 influences muscle fiber-type composition and intramuscular fat content in pigs. PLoS Genet. 2019, 15, e1008279. [CrossRef]

33. Livingston, D.J.; Brown, W.D. The Chemistry of Myoglobin and Its Reactions. Food Technol. 1981, 35, $244-252$.

34. Wittenberg, J.B.; Wittenberg, B.A. Myoglobin function reassessed. J. Exp. Biol. 2003, 206, 2011-2020. [CrossRef] [PubMed]

35. Kim, G.-D.; Jeong, J.-Y.; Hur, S.-J.; Yang, H.-S.; Jeon, J.-T.; Joo, S.-T. The relationship between meat color (CIE L* and a*), myoglobin content, and their influence on muscle fiber characteristics and pork quality. Korean J. Food Sci. Anim. Resour. 2010, 30, 626-633. [CrossRef]

36. Bosch, L.; Tor, M.; Reixach, J.; Estany, J.J.M.S. Age-related changes in intramuscular and subcutaneous fat content and fatty acid composition in growing pigs using longitudinal data. Meat Sci. 2012, 91, 358-363. [CrossRef] [PubMed]

37. Olivares, A.; Daza, A.; Rey, A.; Lopez-Bote, C.J.M.S. Interactions between genotype, dietary fat saturation and vitamin A concentration on intramuscular fat content and fatty acid composition in pigs. Meat Sci. 2009, 82, 6-12. [CrossRef]

38. Straadt, I.K.; Aaslyng, M.D.; Bertram, H.C.J.M.S. Sensory and consumer evaluation of pork loins from crossbreeds between Danish Landrace, Yorkshire, Duroc, Iberian and Mangalitza. Meat Sci. 2013, 95, 27-35. [CrossRef]

39. Kris-Etherton, P.M. AHA Science Advisory. Monounsaturated fatty acids and risk of cardiovascular disease. American Heart Association. Nutrition Committee. Circulation 1999, 100, 1253-1258. [CrossRef]

40. Zhao, X.; Mo, D.; Li, A.; Gong, W.; Xiao, S.; Zhang, Y.; Qin, L.; Niu, Y.; Guo, Y.; Liu, X.J. Comparative analyses by sequencing of transcriptomes during skeletal muscle development between pig breeds differing in muscle growth rate and fatness. PLoS ONE 2011, 6, e19774. [CrossRef]

41. Wang, Y.; Reverter, A.; Mannen, H.; Taniguchi, M.; Harper, G.; Oyama, K.; Byrne, K.; Oka, A.; Tsuji, S.; Lehnert, S. Transcriptional profiling of muscle tissue in growing Japanese Black cattle to identify genes involved with the development of intramuscular fat. Aust. J. Exp. Agric. 2005, 45, 809-820. [CrossRef]

42. Si-Tahar, M.; Merlin, D.; Sitaraman, S.; Madara, J.L. Constitutive and regulated secretion of secretory leukocyte proteinase inhibitor by human intestinal epithelial cells. Gastroenterology 2000, 118, 1061-1071. [CrossRef]

43. Irvin, M.R.; Shrestha, S.; Chen, Y.-D.I.; Wiener, H.W.; Haritunians, T.; Vaughan, L.K.; Tiwari, H.K.; Taylor, K.D.; Scherzer, R.; Saag, M.S. Genes linked to energy metabolism and immunoregulatory mechanisms are associated with subcutaneous adipose tissue distribution in HIV-infected men. Pharm. Genom. 2011, 21, 798. [CrossRef] 
44. Fu, Y.; Li, C.; Tang, Q.; Tian, S.; Jin, L.; Chen, J.; Li, M.; Li, C. Genomic analysis reveals selection in Chinese native black pig. Sci. Rep. 2016, 6, 36354. [CrossRef] [PubMed]

45. Neess, D.; Bek, S.; Engelsby, H.; Gallego, S.F.; Faergeman, N.J. Long-chain acyl-CoA esters in metabolism and signaling: Role of acyl-CoA binding proteins. Prog. Lipid Res. 2015, 59, 1-25. [CrossRef] [PubMed]

46. Pena, R.; Noguera, J.; Casellas, J.; Díaz, I.; Fernández, A.; Folch, J.; Ibáñez-Escriche, N. Transcriptional analysis of intramuscular fatty acid composition in the longissimus thoracis muscle of I berian $\times \mathrm{L}$ andrace back-crossed pigs. Anim. Genet. 2013, 44, 648-660. [CrossRef] [PubMed]

47. Li, L.O.; Klett, E.L.; Coleman, R.A. Acyl-CoA synthesis, lipid metabolism and lipotoxicity. Biochim. Biophys. Acta BBA Mol. Cell Biol. Lipids 2010, 1801, 246-251. [CrossRef]

48. Reiner, G.; Heinricy, L.; Müller, E.; Geldermann, H.; Dzapo, V. Indications of associations of the porcine FOS proto-oncogene with skeletal muscle fibre traits. Anim. Genet. 2002, 33, 49-55. [CrossRef] 